\title{
Pollution and Sustainability Indices for Small and Medium Wastewater Treatment Plants in the Southwest of Spain
}

\author{
M. I. Fernández-Fernández, Pedro T. Martín de la Vega and Miguel A. Jaramillo-Morán * \\ Department of Electrical Engineering, Electronics \& Automation, University of Extremadura, Avda.Elvas s/n, \\ 06006 Badajoz, Spain; marisaff@unex.es (M.I.F.-F.); pedromm@unex.es (P.T.M.d.l.V.) \\ * Correspondence: miguel@unex.es; Tel.: +34-924-289-628
}

Received: 25 February 2019; Accepted: 13 March 2019; Published: 15 March 2019

check for updates

\begin{abstract}
Two indices have been defined in this work to measure the pollution load that a Wastewater Treatment Plant (WWTP) receives and the efficiency of the process it carries out from the overall perspective of pollution removal and energy efficiency. The aim is to provide two performance parameters which could be used to characterize both the working conditions of a WWTP and how well it treats the pollution it receives. In this way, they may be used to compare the behavior of different plants in a certain geographical area. Forty-five WWTPs in the Southwest of Spain were studied to find out the most significant information that is to be used to identify and define both indices. Seven of the variables recorded were used to define each one. Their values were calculated for the whole set of plants studied. The results showed that most of the plants received a low pollution load. Only six of them suffered from a high pollution load, probably because of farms and food industries located in their surroundings. Only three plants showed a poor efficiency, while 23 of them presented a very good one.
\end{abstract}

Keywords: wastewater treatment plants; sustainability evaluation indices; nutrients and organic material removal efficiency

\section{Introduction}

There is no doubt that human activity produces a decrease in the quality of water in rivers, lakes, and seas. The water cycle begins by taking water from one of these sources [1,2]; then, it is processed in drinking water treatment plants to make it fit for human consumption. Once it has been treated, it is delivered through supply systems to be used in human activities. Those activities add pollution to water, which becomes wastewater and flows, thorough the sewer system, toward Wastewater Treatment Plants (WWTP), where pollutants are removed. Then, the treated water is driven into water sources, from which it will be taken again to repeat its cycle [3,4]. Therefore, as water is a finite resource, the treatment process should be as efficient as possible to guarantee that the water quality is good enough to be used again for human activities. To accomplish this aim, the treatment process should provide processed water whose quality should be as good as that taken from natural sources [5]. In other words, WWTPs should remove all pollution (ideal case) added to water by human activities.

Water policies have been successful in protecting water resources, especially by introducing high restrictive limits to water discharges from WWTPs of big urban agglomerations [6]. These limits are related to organic matter (both particulate and soluble) and nutrients (especially ammonia, total nitrogen, and total phosphorus) with the aim of minimizing the eutrophication of water bodies. In this context, there is strong pressure from governments and environmental protection associations to reduce pollutant discharges because water quality is experiencing a severe environmental degradation 
due to the over-exploitation of natural resources and climate change. In this way, as temperature increase in water bodies promotes their eutrophication [7,8], water quality is decreasing [9], although pollution limits are controlled.

These effects are more intense in areas with a great number of small and medium WWTPs, because regulations concerning the quality of effluent water are less restrictive and discharge points and areas have high geographical dispersion. Therefore, controlling the quality of released water and the effect it has on water resources have become complex tasks. Furthermore, industrial discharges into sewer systems in these kinds of WWTPs are harder to control and, therefore, their effect on the treatment process is more dangerous as, at best, they may not be properly processed or, at worst, they could jeopardize the plant integrity. For this reason, the performance control of WWTPs [10] has become a key issue in integral water cycle management.

Several performance indices may be used to measure the quality of the water released by WWTPs and the process performance, although those related to the pollution rejection rates stated by legal regulations and those related to the sustainability of wastewater treatment facilities are preferred. The former measure organic matter (Chemical Oxygen Demand (COD), Biological Oxygen Demand (BOD), and Total Suspended Solid (TSS)) and nutrients (Ammonia, Total Nitrogen (TN), and Total Phosphorus (TP)) in water [11]. The latter are those measuring energy consumption, which are directly related to the carbon footprint of WWTPs, and the effect of industrial discharges into the sewer system. Thus, there are a lot of parameters which may be taken into account when studying WWTPs performance [12]. Nevertheless, when too many parameters are analyzed, it becomes difficult to obtain precise and significant information regarding the performance of the depuration process, as so much data demand a detailed analysis, which consumes a lot of time and effort when carried out. On the other hand, as efficiency is a global concept, it should not rely on particular interpretations of a lot of individual data. Therefore, it would be very useful to carry out a mathematical study with those data to find out which provide the most significant information, so that only they will be considered to study the process efficiency. In addition, not only a reduction of the number of parameters to be considered should be obtained, but mathematical expressions comprising their contributions to the global efficiency should also be proposed in order to define indices which provide significant and objective measurements of the overall efficiency of the treatment process [13,14].

In this work, the operating variables and the removal efficiency of forty-five medium and small WWTPs in the Southwest of Spain were analyzed to find out the most significant ones in the treatment process and to obtain mathematical expressions which could measure their load and efficiency in a simple way. Variables describing the influent water characteristics, comprising input flow, pollutants, number of detected industrial discharges, and energy consumption, were studied to find out their effects on the removal efficiency. In addition, the removal rates of pollutants were evaluated to study their effects on the process sustainability. Principal Component Analysis was applied to the whole set of data to identify those variables providing most of the information needed to properly characterize the process behavior. Then, they were analyzed by means of biplot graphics to find out relations between them, which could be used to define a load index and a sustainability one for WWTPs. These indices were defined by considering only the parameters with a greater influence on the information they provide. In this way, they could be used to evaluate the performance of any WWTP, regardless of its load, localization, and treated water volume, by taking into account only a reduced set of the variables usually used to study the working conditions of a WWTP. They could also be used to study geographical patterns of WWTP discharges and to identify the effect that industrial activities have in water bodies. 


\section{Materials and Methods}

\subsection{Research Area and Materials}

The forty-five Wastewater Treatment Plants studied in this work are located in the province of Badajoz (Southwest of Spain). It covers an area of $21.760 \mathrm{~km}^{2}$ (Figure 1). All these plants have the same configuration, which is the most widespread in the Southwest of Spain: the Activated Sludge Process (ASP) carried out in an oxidation ditch vessel. They were weekly monitored for three years. The data used to carry out the analysis proposed in this work were monthly averages of the operating variables of the input and output flows of each treatment plant. Twelve variables describing the working conditions of the plant, related to both influent and effluent water, were measured: Input Flow (IF), Output Flow (OF), Energy Consumption (EC), Number of Industrial Discharges (NID), Chemical Oxygen Demand (COD), Biological Oxygen Demand (BOD), Ammonia $\left(\mathrm{NH}_{4}{ }^{+}\right.$), Total Nitrogen (TN), Total Phosphorus (TP), Total Suspended Solids (TSS), pH, and Conductivity. Energy Consumption was obtained from

$$
E C\left(\frac{K w}{\text { month }}\right)=M I F \times C R
$$

where MIF defines the Monthly Input Flow in $\mathrm{m}^{3} /$ month and $C R$ represents the Consumption Ratio in $\mathrm{Kw} / \mathrm{m}^{3}$.

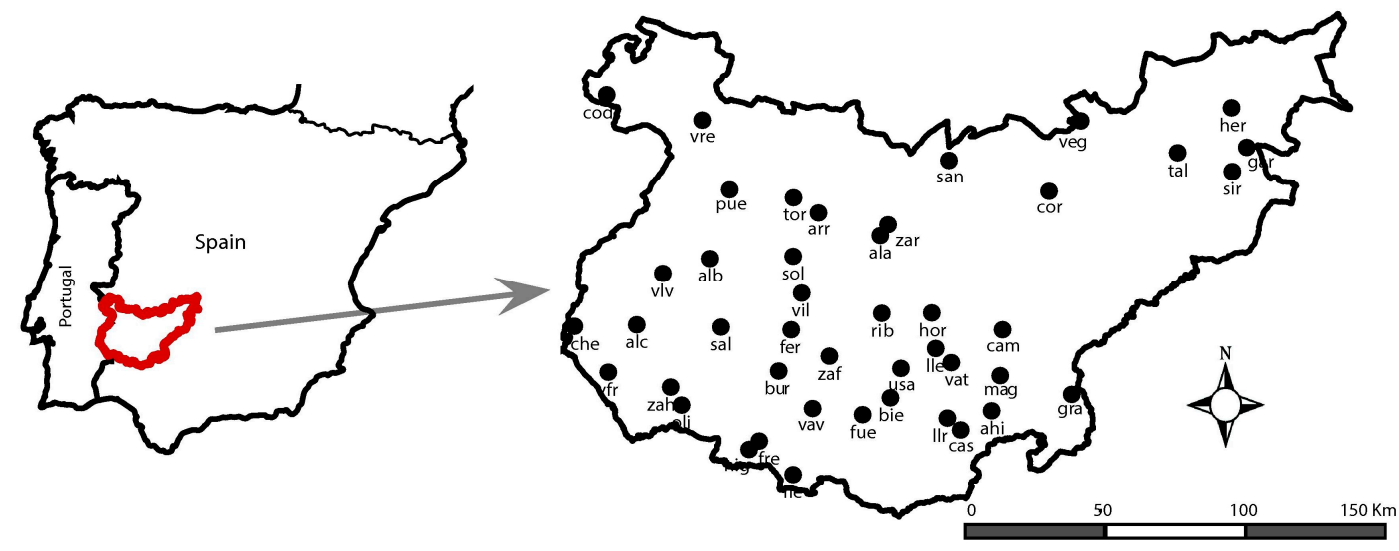

$\begin{array}{lll}\text { ahi: Ahillones } & \text { che: Cheles } & \text { her: Herrera del Duque } \\ \text { ala: Alange } & \text { cod: La Codosera } & \text { hig: Higuera la Real } \\ \text { alb: La Albuera } & \text { cor: La Coronada } & \text { hor: Hornachos } \\ \text { alc: Alconchel } & \text { fer: Feria } & \text { Ile: Llera } \\ \text { arr: Arroyo de San Serván } & \text { fre: Fregenal de la Sierra } & \text { Ilr: Llerena } \\ \text { bie: Bienvenida } & \text { fue: Fuente de Cantos } & \text { mag: Maguilla } \\ \text { bur: Burguillos del Cerro } & \text { fle: Fuentes de Leon } & \text { nav: Navalvillar de Pela } \\ \text { cam: Campillo de Llerena } & \text { gar: Garbayuela } & \text { oli: Oliva de la Frontera } \\ \text { cas: Casas de Reina } & \text { gra: Granja de Torrehermosa } & \text { pue: Pueblonuevo }\end{array}$

$\begin{array}{ll}\text { rib: Ribera del Fresno } & \text { vav: Valencia del Ventoso } \\ \text { sal: Salvaleón } & \text { vlv: Valverde de Leganés } \\ \text { san: Santa Amalia } & \text { veg:Vegas Altas } \\ \text { sir: Siruela } & \text { vil: Villalba de los Barros } \\ \text { sol: Solana de los Barros } & \text { vfr: Villanueva del Fresno } \\ \text { tal: Talarrubias } & \text { vre: Villar del Rey } \\ \text { tor: Torremayor } & \text { zaf: Zafra } \\ \text { usa: Usagre } & \text { zah: Zahinos } \\ \text { vat: Valencia de las Torres } & \text { zar: La Zarza }\end{array}$

Figure 1. Spatial distribution of the WWPTs studied in the area of Badajoz, name of each plant, and their corresponding codes.

The removal efficiency of the treatment process for each variable was obtained by comparing concentrations in influent $\left(C_{s i}\right)$ and effluent $\left(C_{s o}\right)$ water:

$$
R=\frac{C_{s i}-C_{s o}}{C_{s i}} \times 100 \%
$$

Those variables were obtained according to standard methods for wastewater treatment analysis [15]. The whole data set has been analyzed to define two indices: one to provide a measure of the load a plant receives and the other to describe the overall efficiency of the treatment process it carries out, that is to say, its sustainability. 
Only eleven variables were considered to study the input load, because Output Flow is not related to this concept. Therefore, the variables (and their units and codes for its subsequent study) considered to define the input load were: Energy Consumption (Kw/month, X1), Input Flow ( $\mathrm{m}^{3}$, X2), Number of Industrial Discharges (X3), Total Suspended Solids (mg/L, X4), Chemical Oxygen Demand (mg/L, X5), Biological Oxygen Demand (mg/L, X6), Total Nitrogen (mg/L, X7), Total Phosphorus (mg/L, X8), $\mathrm{pH}(\mathrm{X} 9)$, Conductivity $(\mu \mathrm{S} / \mathrm{cm}, \mathrm{X} 10)$, and Ammonia (mg/L, X11). Their statistical values for the whole set of plants are shown in Table 1.

Table 1. Statistics of variables recorded from the whole set of plants analyzed.

\begin{tabular}{|c|c|c|c|c|}
\hline & Media & Standard Deviation & Maximum & Minimum \\
\hline EC (Kw/month) & 10,134 & 6147 & 34,393 & 950 \\
\hline IF $\left(\mathrm{m}^{3} /\right.$ month $)$ & 30,232 & 21,010 & 105,734 & 553 \\
\hline $\mathbf{E F}\left(\mathrm{m}^{3} / \mathrm{month}\right)$ & 27,190 & 10,020 & 90,321 & 380 \\
\hline NID & 1.33 & 2.80 & 9 & 0 \\
\hline $\operatorname{COD}(\mathrm{mg} / \mathrm{L})$ & 345 & 126 & 624 & 95 \\
\hline BOD (mg/L) & 164 & 59 & 303 & 55 \\
\hline $\mathrm{pH}$ & 7.19 & 0.40 & 8.46 & 6.30 \\
\hline Conductivity $(\mathrm{S} / \mathrm{cm})$ & 849 & 173 & 1178 & 315 \\
\hline $\mathrm{NH}_{4}{ }^{+}(\mathrm{mg} / \mathrm{L})$ & 24.89 & 9.57 & 46.46 & 4.57 \\
\hline $\mathbf{T N}(\mathrm{mg} / \mathrm{L})$ & 59.00 & 15.64 & 76.32 & 17.82 \\
\hline $\mathbf{T P}(\mathrm{mg} / \mathrm{L})$ & 6.53 & 3.16 & 16.50 & 1.71 \\
\hline TSS (mg/L) & 228 & 120 & 733 & 43.25 \\
\hline
\end{tabular}

In the same way, only ten variables were considered to analyze the removal efficiency, as Conductivity and $\mathrm{pH}$ have no influence on this concept. In this way, the process sustainability was defined by taking into account only the following variables (and their units and codes for its subsequent study) and removal rates: Energy Consumption (Kw/month, Z1), Input Flow ( $\left.\mathrm{m}^{3}, \mathrm{Z2}\right)$, Output Flow $\left(\mathrm{m}^{3}, \mathrm{Z3}\right)$, Number of Industrial Discharges (Z4), Biological Oxygen Demand Removal Efficiency (\%, Z5), Chemical Oxygen Demand Removal Efficiency (\%, Z6), Total Suspended Solids Removal Efficiency(\%, Z7), Total Nitrogen Removal Efficiency (\%, Z8), Total Phosphorus Removal Efficiency (\%, Z9), and Ammonia Removal Efficiency (\%, Z10). Their statistical values for the whole set of plants are shown in Table 2.

Table 2. Statistics of the removal efficiencies for the whole set of plants analyzed.

\begin{tabular}{ccccc}
\hline & Media & Standard Deviation & Maximum & Minimum \\
\hline COD (\%) & 90 & 7 & 96 & 56 \\
BOD (\%) & 92 & 7 & 97 & 54 \\
NH $_{4}^{+}(\%)$ & 86 & 10 & 98 & 42 \\
TN (\%) & 74 & 11 & 88 & 37 \\
TP (\%) & 68 & 12 & 86 & 38 \\
TSS (\%) & 94 & 4 & 98 & 79 \\
\hline
\end{tabular}

\subsection{Methods}

The definition of those two indices must be based on the variables related to each one. Nevertheless, using them all to do that could be cumbersome and their corresponding mathematical expression may be hard to use. Therefore, only a reduced set of them should be selected to define each index: those providing the most significant information.

Principal Component Analysis (PCA) is a statistical tool widely used to study relationships between variables, defining a data set in order to reduce the dimension of their data vectors [16,17]. In other words, it highlights relationships between those variables (the component of each data vector) and allows the number of components needed to properly characterize the whole data set to be reduced. To do that, the algorithm provides a new set of variables, known as principal components (PC), obtained as a linear combination of the original ones. They are arranged in decreasing order of 
the variance each one explains, so that only those with higher values of that variance may be taken into account to represent the original data set.

In this work, PCA has been carried out by means of eigenvalue decomposition of the covariance matrix of data, as values of each variable were centered and normalized to variance one before being processed to guarantee that each one was equally treated, regardless of the range their values had. The eigenvalue associated with a given PC measures the variance in all the variables accounted for by that PC. Nevertheless, using this tool requires that the variables to be processed ought to be correlated [17]. Therefore, correlations between then should be studied. Pearson correlation coefficients provide that information. They are arranged in a matrix structure where values close to 1 point to a high correlation between two variables, those close to -1 point to an inverse correlation, and those close to 0 show that no correlation exists. Therefore, two matrices were obtained: one for variables related to the input load and the other for those related to the removal efficiency (Tables 3 and 4 ). It may be seen in these tables that a number of those variables are more or less correlated, a fact that justifies using PCA to obtain a reduced set of them to characterize the treatment process and then to define the two indices describing load and sustainability.

Table 3. Pearson correlation coefficients for variables related to input load.

\begin{tabular}{cccccccccccc}
\hline & $\mathbf{X 1}$ & $\mathbf{X}$ & $\mathbf{X 3}$ & $\mathbf{X 4}$ & $\mathbf{X 5}$ & $\mathbf{X 6}$ & $\mathbf{X 7}$ & $\mathbf{X 8}$ & $\mathbf{X 9}$ & $\mathbf{X 1 0}$ & $\mathbf{X 1 1}$ \\
\hline $\mathbf{X 1}$ & 1.000 & 0.551 & 0.210 & -0.031 & -0.058 & 0.054 & -0.146 & 0.123 & -0.101 & 0.014 & -0.0008 \\
$\mathbf{X 2}$ & 0.551 & 1.000 & 0.076 & 0.005 & 0.068 & 0.137 & -0.022 & 0.082 & 0.037 & 0.004 & 0.091 \\
$\mathbf{X 3}$ & 0.210 & 0.076 & 1.000 & 0.666 & 0.398 & 0.294 & 0.070 & 0.499 & 0.097 & 0.384 & 0.095 \\
$\mathbf{X 4}$ & -0.031 & 0.005 & 0.666 & 1.000 & 0.667 & 0.505 & 0.429 & 0.533 & 0.469 & 0.399 & 0.386 \\
$\mathbf{X 5}$ & -0.058 & 0.068 & 0.398 & 0.667 & 1.000 & 0.926 & 0.517 & 0.398 & 0.844 & 0.583 & 0.734 \\
$\mathbf{X 6}$ & 0.054 & 0.137 & 0.294 & 0.505 & 0.926 & 1.000 & 0.472 & 0.288 & 0.809 & 0.604 & 0.801 \\
$\mathbf{X 7}$ & -0.146 & -0.022 & 0.070 & 0.429 & 0.514 & 0.472 & 1.000 & 0.489 & 0.478 & 0.495 & 0.612 \\
$\mathbf{X 8}$ & 0.123 & 0.082 & 0.499 & 0.533 & 0.398 & 0.288 & 0.489 & 1.000 & 0.228 & 0.530 & 0.419 \\
$\mathbf{X 9}$ & -0.101 & 0.037 & 0.097 & 0.469 & 0.844 & 0.809 & 0.478 & 0.228 & 1.000 & 0.435 & 0.745 \\
$\mathbf{X 1 0}$ & 0.014 & 0.004 & 0.384 & 0.399 & 0.583 & 0.604 & 0.495 & 0.530 & 0.435 & 1.000 & 0.657 \\
$\mathbf{X 1 1}$ & -0.0008 & 0.091 & 0.095 & 0.386 & 0.734 & 0.801 & 0.612 & 0.419 & 0.745 & 0.657 & 1.000 \\
\hline
\end{tabular}

Table 4. Pearson correlation coefficients for variables related to removal efficiency.

\begin{tabular}{ccccccccccc}
\hline & $\mathbf{Z 1}$ & $\mathbf{Z 2}$ & $\mathbf{Z 3}$ & $\mathbf{Z 4}$ & $\mathbf{Z 5}$ & $\mathbf{Z 6}$ & $\mathbf{Z 7}$ & $\mathbf{Z 8}$ & $\mathbf{Z 9}$ & $\mathbf{Z 1 0}$ \\
\hline $\mathbf{Z 1}$ & 1.000 & 0.551 & 0.544 & 0.341 & -0.083 & 0.160 & 0.328 & 0.189 & -0.155 & -0.309 \\
$\mathbf{Z 2}$ & 0.551 & 1.000 & 0.978 & 0.081 & 0.003 & 0.035 & 0.137 & -0.095 & -0.033 & -0.538 \\
$\mathbf{Z 3}$ & 0.544 & 0.978 & 1.000 & 0.0009 & -0.036 & -0.004 & 0.114 & -0.121 & -0.085 & -0.560 \\
$\mathbf{Z 4}$ & 0.341 & 0.081 & 0.0009 & 1.000 & 0.195 & 0.171 & 0.113 & 0.099 & 0.038 & 0.127 \\
$\mathbf{Z 5}$ & -0.083 & 0.003 & -0.036 & 0.195 & 1.000 & 0.719 & 0.666 & 0.635 & 0.566 & 0.630 \\
$\mathbf{Z 6}$ & 0.160 & 0.035 & -0.004 & 0.171 & 0.719 & 1.000 & 0.899 & 0.845 & 0.547 & 0.511 \\
$\mathbf{Z 7}$ & 0.328 & 0.137 & 0.114 & 0.113 & 0.666 & 0.899 & 1.000 & 0.870 & 0.373 & 0.383 \\
$\mathbf{Z 8}$ & 0.189 & -0.095 & -0.121 & 0.099 & 0.635 & 0.845 & 0.870 & 1.000 & 0.491 & 0.587 \\
$\mathbf{Z 9}$ & -0.155 & -0.033 & -0.085 & 0.038 & 0.566 & 0.547 & 0.373 & 0.491 & 1.000 & 0.359 \\
$\mathbf{Z 1 0}$ & -0.309 & -0.538 & -0.560 & 0.127 & 0.630 & 0.511 & 0.383 & 0.587 & 0.359 & 1.000 \\
\hline
\end{tabular}

Once correlations between variables in both data sets were stated, PCA was applied to each one. Tables 5 and 6 show the eigenvalue, explained variance (\%), and accumulated variance (\%) of each principal component for input load and removal efficiency. Several techniques have been defined to select the set of PCs which may be assumed as representative enough of the whole data set [18]. One of them is Kaiser's rule [19]. It states that only those PCs with eigenvalues higher than 1.0 should be selected. Another proposes selecting only those whose accumulated variance explains more than $70 \%[17,18]$. A third rule, the scree plot method [20], looks for a change or "break point" in the decreasing curve plotting the variance of each PC and selects those before that point [21]. Studies have probed this tool to be an accurate rule to find out the number of PCs to be selected as representative enough of the whole set of variables [22]. The scree plots related to both data sets are shown in Figure 2. 
Table 5. Percentage of variance of the eleven PCs related to input load.

\begin{tabular}{cccc}
\hline Principal Component & Eigenvalue & Explained Variance (\%) & Accumulated Variance (\%) \\
\hline PC1X & 2.225 & 45.00 & 45.00 \\
PC2X & 1.3826 & 17.38 & 62.37 \\
PC3X & 1.0991 & 10.98 & 73.36 \\
PC4X & 0.99354 & 8.974 & 82.329 \\
PC5X & 0.86110 & 6.741 & 89.070 \\
PC6X & 0.72233 & 47.73 & 93.814 \\
PC7X & 0.51213 & 23.84 & 96.198 \\
PC8X & 0.41370 & 1.556 & 97.754 \\
PC9X & 0.34815 & 1.102 & 98.856 \\
PC10X & 0.31537 & 0.904 & 99.760 \\
PC11X & 0.1625 & 0.24 & 100 \\
\hline
\end{tabular}

Table 6. Percentage of variance of the ten PCs related to removal efficiency.

\begin{tabular}{cccc}
\hline Principal Component & Eigenvalue & Explained Variance (\%) & Accumulated Variance (\%) \\
\hline PC1Z & 1.9973 & 39.89 & 39.89 \\
PC2Z & 1.6207 & 26.27 & 66.16 \\
PC3Z & 1.0781 & 11.62 & 77.78 \\
PC4Z & 0.99811 & 9.962 & 87.743 \\
PC5Z & 0.7576 & 5.74 & 93.48 \\
PC6Z & 0.5148 & 2.65 & 96.13 \\
PC7Z & 0.45537 & 2.074 & 98.208 \\
PC8Z & 0.33117 & 1.097 & 99.304 \\
PC9Z & 0.23082 & 0.533 & 99.837 \\
PC10Z & 0.12759 & 0.163 & 100 \\
\hline
\end{tabular}

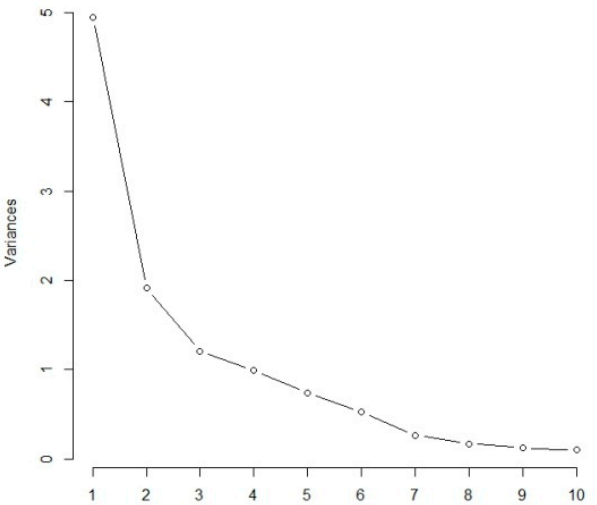

(a)

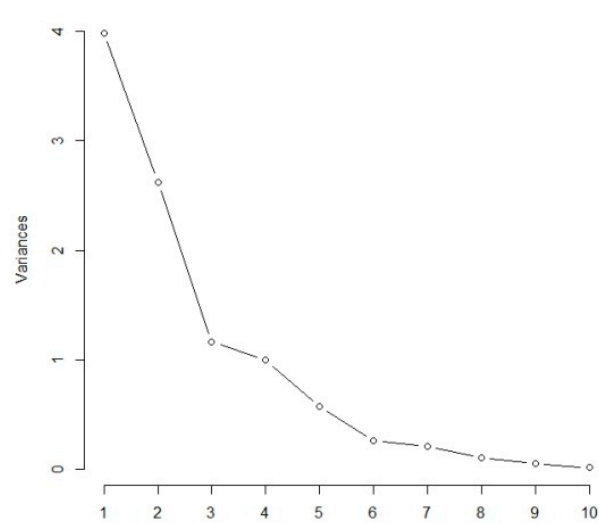

(b)

Figure 2. Scree plots of variance vs. PCs for load (a) and sustainability (b).

Taking into account those three rules, the first three PCs of both input load and removal efficiency have been selected to represent each data set.

The definition of the expressions describing the two aforementioned indices must be carried out by taking into account those variables related to the three PCs selected from PCA. Therefore, they should be mathematical equations made up with some of them: those providing the most significant information about the concept they are to define. Because of this, the relationship between the selected PCs and the variables making them up should be established in order to identify which of those variables should be selected. This can be done with a graphical tool: biplot graphics [23]. They provide a bi-dimensional plot of two PCs, where the variables from which those PCs were obtained are projected onto. This representation allows the relationships between the variables 
projected to be studied. Only those far from the biplot center will be taken into account, because only they are statically well-explained in this representation. Variables close to each other may be assumed as correlated. Variables connected with a $180^{\circ}$ rotation are inversely correlated, whereas variables connected with a $90^{\circ}$ rotation are independent.

Biplots obtained for input load and removal efficiency are shown in Figures 3 and 4, respectively. They present only PC1 vs. PC2 and PC1 vs. PC2 because PC2 vs. PC3 did not provide significant information about both data sets. These biplots only show the variables with higher weights in the first three PCs, which are those selected following the aforementioned rules. For input load, they were Energy Consumption (EC, X1), Input Flow (IF, X2), Number of Industrial Discharge (NID, X3), Total Suspended Solid (TSS, X4), Chemical Oxygen Demand (COD, X5), Biological Oxygen Demand (BOD, X6), and Total Nitrogen (TN, X7).

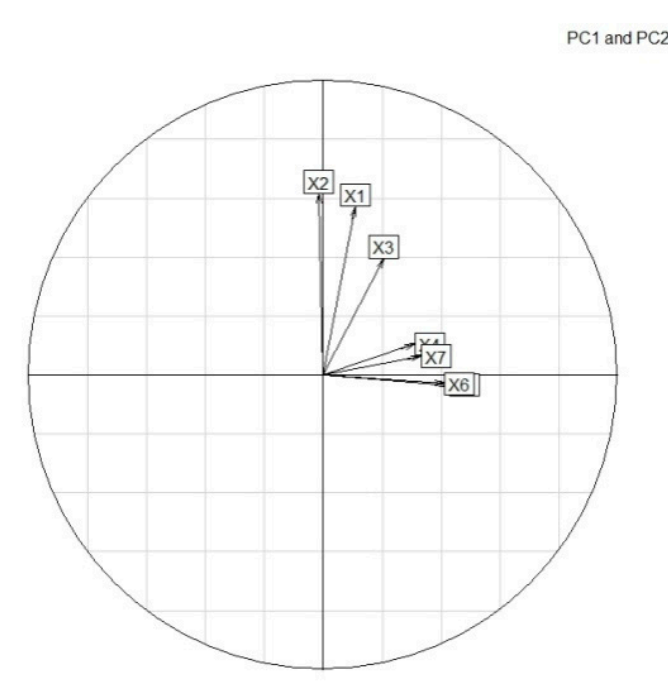

(a)

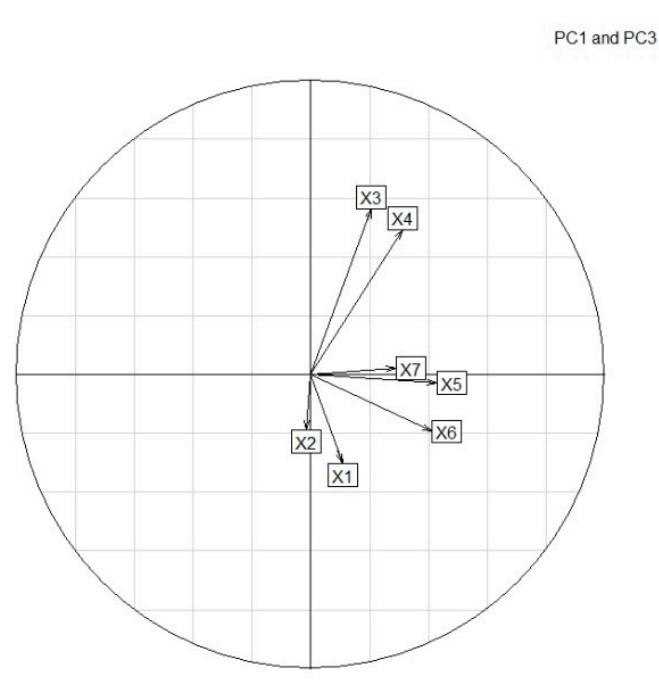

(b)

Figure 3. Biplot graphics for input parameters (with PC1 as X-axis). (a) PC1 vs. PC2. (b) PC1 vs. PC3.

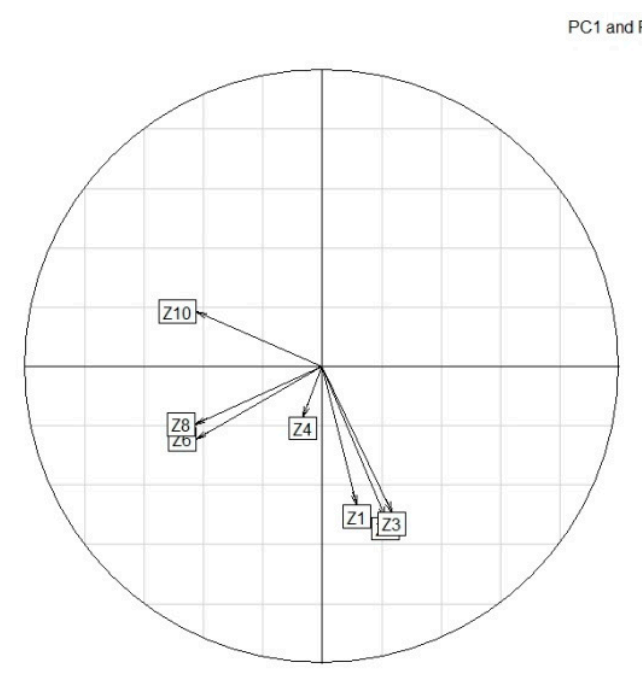

(a)

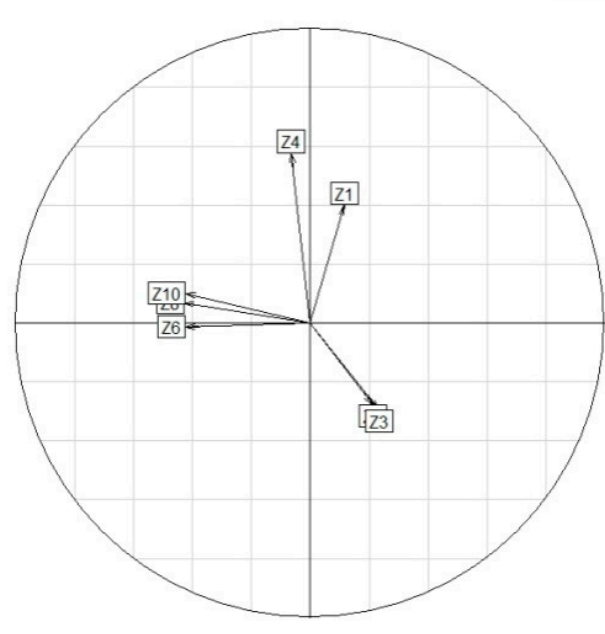

(b)

Figure 4. Biplot graphics for removal efficiency (with PC1 as X-axis). (a) PC1 vs. PC2. (b) PC1 vs. PC3. 
Figure 3a depicts PC1X vs. PC2X. It shows a strong correlation between Energy Consumption (X1), Input Flow (X2), and Number of Industrial Discharges (X3), which are closely related to PC2X (Y-axis). Therefore, it may be concluded that a high Input Flow (X2) with a high Number of Industrial Discharge (X3) demands high Energy Consumption (X1), as it may be expected. In addition, a strong correlation may also be seen between all pollution load parameters: Chemical Oxygen Demand (X5), Biological Oxygen Demand (X6), Total Nitrogen (X7), and Total Suspended Solids (X4). They are related to PC1X (X-axis). However, it is worth noting that there is no correlation between the first set of variables and the second, a fact that suggests that Energy Consumption highly depends on the total amount of input pollution, but not on the nature and concentration of those pollutants.

Figure $3 b$ shows a correlation between Number of Industrial Discharges (X3) and Total Suspended Solids (X4), which are slightly related to PC3X (Y-axis). A correlation between Chemical Oxygen Demand (X5), Organic Matter (X6), and Total Nitrogen (X7) (associated to PC1X: X-axis) may also be seen, which are not correlated with Number of Industrial Discharges (X3) and Total Suspended Solids (X4). Although a slight correlation appears between Energy Consumption (EC, X1) and Input Flow (IF, $\mathrm{X} 2$ ), it is not considered because Energy Consumption (EC, X1) is close to the biplot center, and then, as stated above, it has no statistical significance.

Figure 4 shows biplots describing the nutrient and organic matter removal efficiency. The variables with the highest influence on the first three PCs are: Energy Consumption (EC, Z1), Input Flow (IF, Z2), Output Flow (OF, Z3), Number of Industrial Discharges (NID, Z4), Chemical Oxygen Demand Removal Efficiency (CODRE, Z6), Total Nitrogen Removal Efficiency (TNRE, Z8), and Ammonia Removal Efficiency $\left(\mathrm{NH}_{4} \mathrm{RE}, \mathrm{Z10}\right)$. A strong correlation may be seen in Figure 4a between Energy Consumption (Z1), Input Flow (Z2), and Output Flow (Z3), which are associated with PC2Z (Y-axis). A low correlation appears between Chemical Oxygen Demand Removal Efficiency (Z6), Total Nitrogen Removal Efficiency (Z8), and Ammonia Removal Efficiency (Z10) (although Z6 and Z8 are strongly correlated between them). They are associated with PCZ (X-axis). As Number of Industrial Discharges (NID, Z4) is close to the biplot center, it is not taken into account.

Figure $4 \mathrm{~b}$ shows that there is a strong correlation between Chemical Oxygen Demand Removal Efficiency (Z6), Total Nitrogen Removal Efficiency (Z8), and Ammonia Removal Efficiency (Z10), which are associated with PCZ-1 (X-axis). Energy Consumption (Z1) and Number of Industrial Discharges (Z4) are also correlated and associated with PC3Z (Y-axis). Input Flow (IF, Z2) and Output Flow (OF, $\mathrm{Z3}$ ) have a strong correlation, but they may not be associated with one of the PCs.

\subsection{Load and Sustainability Indices in Small Wastewater Treatment Plants}

The load and sustainability indices will be defined by taking into account the information provided by the analysis carried out above. The first one will measure the pollutant load a plant receives, while the second will describe the efficiency and sustainability of the process, that is to say, how efficiently it is carried out from the combined point of view of pollution removal efficiency and energy saving. They will be defined as a linear combination of the most representative variables of the process that each one measures. Therefore, only the seven variables represented in the biplots associated with each index will be considered to define them. Therefore, those sets of variables (one for each index) and the statistical values associated with the PCs from which they were obtained will be used to make up both indices.

\subsubsection{Load Index: LI}

This index evaluates the load of nutrients and organic matter in the input flow of a WWTP. It is made up of three summands, each one associated with a PC, which are obtained as the product of the normalized variance of each PC by the sum of the normalized variables related to that PC, as pointed out by biplots. The normalized variance represents the variance associated with a PC divided by the sum of the variances of the other three PCs. The normalized value of Input Flow was obtained by dividing it by the maximum value recorded for the plant considered. The normalized values of the 
other variables were obtained by dividing them by its maximum value, as stated in legal requirements regarding WWTP load in the area studied. Taking into account the information provided by the analysis of biplots in Figure 3, the variables associated with each PC are: X5, X6, and X7 to PC1X; X1, $X 2$, and $X 3$ to PC2X; X3 and $X 4$ to PC3X. X4 has not been considered as associated with PC1X because, although it was correlated to X5, X6, and X7 in biplot PC1X-PC2X, it was not in biplot PC1X-PC3X. Therefore, the mathematical expression of this index is

$$
\begin{aligned}
L I=\frac{V_{P C 1 X}}{\sum V} \frac{1}{3}\left(\frac{C O D}{C O D_{N}}+\right. & \left.\frac{B O D}{B O D_{N}}+\frac{T N}{T N_{N}}\right)+\frac{V_{P C 2 X}}{\sum V} \frac{1}{3}\left(\frac{I F}{M I F}+\frac{E C}{M E C}+\frac{N I D}{M N I D}\right) \\
& +\frac{V_{P C 3 X}}{\sum V} \frac{1}{2}\left(\frac{N I D}{M N I D}+\frac{T S S}{\sum T S S_{N}}\right)
\end{aligned}
$$

As the values of all variables and parameters used are normalized, the value of this index ranges from 0 to 1 (to ensure this, every summand is divided by the number of elements it comprises). Values close to 0 point to a low pollution load, while higher ones show a high load.

\subsubsection{Sustainability Index: SI}

This index evaluates how efficient the treatment process of a certain plant is by considering not only its removal efficiency, but also its energy consumption. Variables related to removal efficiency (CODRE, TNRE, and $\mathrm{NH}_{4} \mathrm{RE}$ ) range from 0 to 1 from the sake of normalization. The other variables (EC, IF, OF, and NID) are normalized by dividing their values by their corresponding maximum for each plant. Their contribution to the index is expressed as one minus the variable because the higher their values, the lower the sustainability of the process. In the same way, the lower their values, the higher their contributions to that sustainability. Therefore, from the analysis of the biplots of Figure 4, the variables associated with each PC are: Z6, Z8, and Z10 to PC1Z; Z1, Z2, and Z3 to PC2Z; $\mathrm{Z1}$ and $\mathrm{Z} 4$ to PC3Z. Considering this, the expression describing this index is

$$
\begin{gathered}
S I=\frac{V_{P C 1 Z}}{\sum V} \frac{1}{3}\left(C O D R E+T N R E+N H_{4} R E\right)+\frac{V_{P C 2 Z}}{\sum V} \frac{1}{3}\left[\left(1-\frac{E C}{E C_{M}}\right)+\left(1-\frac{I F}{I F_{M}}\right)+\left(1-\frac{O F}{O F_{M}}\right)\right] \\
+\frac{V_{P C 3 Z}}{\sum V} \frac{1}{2}\left[\left(1-\frac{E C}{E C_{M}}\right)+\left(1-\frac{N I D}{N I D_{M}}\right)\right]
\end{gathered}
$$

Its values also range between 0 and 1 . Those close to 0 point to a low sustainability of the treatment process, while a better performance is associated with higher values.

\section{Results and Discussion}

The Load and Sustainability Indices were calculated for each one of the forty-five WWTPs studied in this work.

Figure 5 and Table 7 show the Load Index of each plant. They have a great dispersion in their values, although they describe a relative low pollution load, with values lower than 0.5 in all plants. About half of them are lower than 0.2 (Table 7). The other 22 plants have an index lower than 0.25 and six of them have values lower than 0.15 . It is worth noting that all these plants presented low Energy Consumption. Those low values of the Load Index show that they received a low pollution load of nutrients and organic matter, as is typical in rural areas such as those where these plants are located. The rest of the plants (23) have a Load Index higher than 0.25 . Those with values between 0.25 and 0.35 (17 plants) presented high concentrations of organic matter in their input load. This fact may be explained by the great number of farms located in their environment. The remaining six plants (those with an index higher than 0.35 ) had very high pollution loads due to the presence of farms and food industries in their environment, which generated a significant Number of Industrial Discharges. The plant of Higuera la Real is especially outstanding (it had the highest index: $L I=0.47$ ), in which very high concentrations of organic matter and total nitrogen were measured in its input load along with high Energy Consumption. In addition, a high Number of Industrial Discharges were also recorded, which were released by the large number of food industries located in this village. 


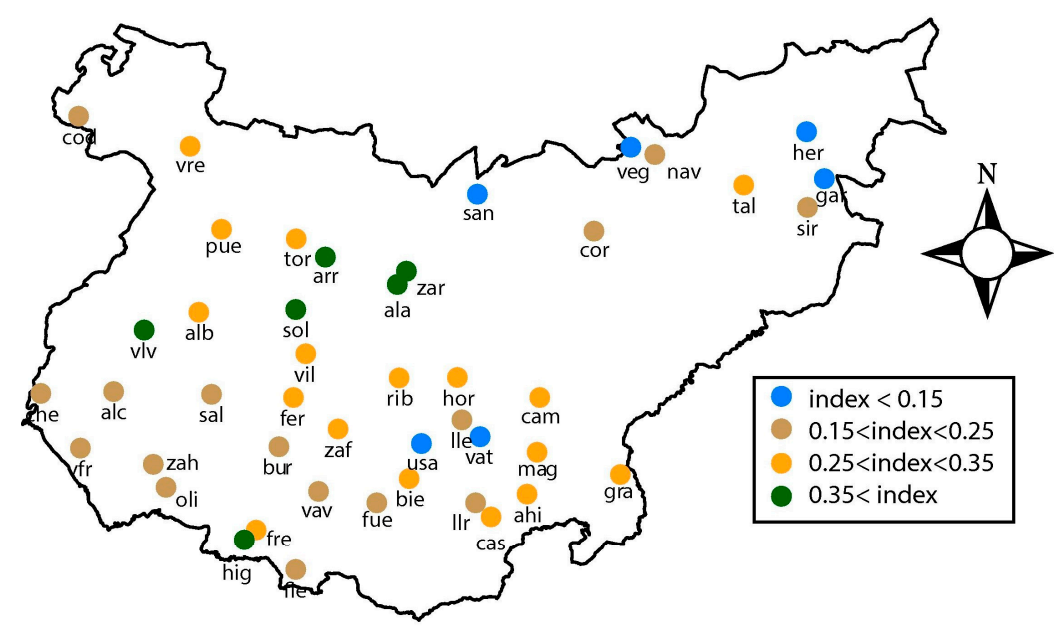

Figure 5. Load Index for each one of the plants studied.

Table 7. Summary of Load Index.

\begin{tabular}{ccc}
\hline Index Value & Plants & Plants Feature \\
\hline$<0.15$ & gar, her, san, usa, vat, veg & $\begin{array}{c}\text { Low nutrient (TN) and organic matter load and low } \\
\text { Energy Consumption }\end{array}$ \\
\hline $0.15-0.25$ & $\begin{array}{c}\text { alc, bur, che, fue, fle, cod, cor, lle, llr, } \\
\text { nav, oli, sal, sir, vav, vfr, zah }\end{array}$ & Medium load of organic matter (TSS) \\
\hline $0.25-0.35$ & $\begin{array}{c}\text { ahi, alb, bie, cam, cas, fer, fre gra, hor, } \\
\text { mag, pue, rib, tal, tor, vil, vre, zaf }\end{array}$ & High load of organic matter (COD and TSS) \\
\hline ala, arr, hig, zar, sol, vlv & $\begin{array}{c}\text { High Number of Industrial Discharge, high load of } \\
\text { Total Nitrogen and organic matter (TSS and COD) } \\
\text { and high Energy Consumption }\end{array}$ \\
\hline
\end{tabular}

The geographical distribution of this index shows that some of the plants with the highest load (four of them: zar, ala, sol, arr) are located in the same area. This fact suggests that they may have similar pollution problems. In fact, they are surrounded by a lot of farms and food industries, as pointed out above. In this way, the Load Index may be a useful tool to identify pollution from industrial discharges so that specific treatment strategies can be defined to be implemented in WWTPs to efficiently deal with it, as pointed out in [10], where specific studies are suggested to improve the treatment of this kind of pollution. This fact defines a challenging problem because, as pointed out before, those plants suffering from a high number of Industrial Discharges also demanded high Energy Consumption. Therefore, developing and implementing effective treatment strategies to remove that pollution will also help to reduce Energy Consumption. So, as stated in [12], the joint analysis of a number of key parameter indicators, such as those used in the present work, may help to improve energy savings in treatment processes. This fact may also provide a significant reduction of the carbon footprint of the WWTP.

Four of the six plants with lower pollution loads (values lower than 0.15) are located in the Northeast of the area studied, while the highest values are located in its center. It may also be seen in Figure 5 that plants in the Southwest of the province show a low pollution load. These facts point out a certain geographical distribution of pollution patterns which could be provided by similar pollution profiles related to social and economic factors. Therefore, similar treatment strategies could be defined to be implemented in plants in a certain area with similar pollution patterns. In this way, the public agency supervising wastewater treatment could suggest common strategies to enterprises in charge of managing those plants to deal with those common pollution profiles. In addition, new strategies could be tested only in a certain plant as their results may be useful for the whole set of plants suffering from the same pollution load.

The Sustainability Index was also obtained for all plans studied in this work. The results may be seen in Figure 6 and Table 8. Only three plants present a poor efficiency, with indices lower than 0.75 . 
Those values were provided by low nutrient removal efficiencies $\left(\mathrm{TN}\right.$ and $\mathrm{NH}_{4}$ ) and a high Number of Industrial Discharges. This fact may explain the low sustainability indices observed in these three plants. It is worth noting that two of them (Zafra and Torremayor) also presented high values of Energy Consumption. Values between 0.75 and 0.85 are observed in 19 plants. Their ammonia removal efficiencies were low, but their organic matter removal efficiencies were good; they also had a low Number of Industrial Discharges. Finally, 23 plants present values higher than 0.85 . They had high nutrient and organic matter removal efficiencies with a low Number of Industrial Discharges and low Energy Consumption. These data point out that these plans are well-managed, as those good removal rates were reached with moderate Energy Consumption. The low Number of Industrial Discharges recorded in those plants may also have helped to achieve those good results.

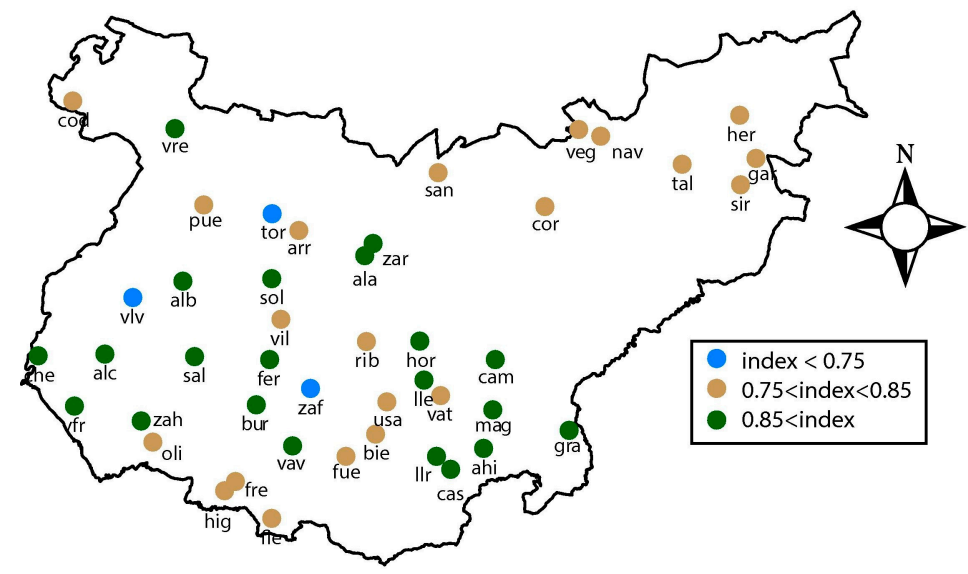

Figure 6. Sustainability Index for each one of the plants studied.

Table 8. Summary of Sustainability Index.

\begin{tabular}{ccc}
\hline Index Value & Plants & Plant Features \\
\hline$<0.75$ & tor, vlv, zaf & $\begin{array}{c}\left.\text { Low nutrient removal efficiency (TN and NH } \mathrm{N}_{4}\right), \text { high Number } \\
\text { of Industrial Discharge and high Energy Consumption }\end{array}$ \\
\hline $0.75-0.85$ & $\begin{array}{c}\text { arr, bie, fre, fue, gar, her, hig, cod, } \\
\text { cor, nav, oli, pue, rib, san, tal usa, } \\
\text { vat, veg, vil }\end{array}$ & $\begin{array}{c}\text { Low nutrient }\left(\mathrm{NH}_{4}\right) \text { removal efficiency but high organic } \\
\text { matter removal efficiency }\end{array}$ \\
\hline 0.85 & $\begin{array}{c}\text { ahi, ala, alb, alc, bur, cam, cas, che, } \\
\text { fer, fue, gra, hor, lle, llr, mag, sal, } \\
\text { sir, sol, vav, vre, vfr, zah, zar }\end{array}$ & $\begin{array}{c}\text { High nutrient and organic matter removal efficiency, low } \\
\text { Number of Industrial Discharge and low Energy Consumption }\end{array}$ \\
\hline
\end{tabular}

From the analysis of the geographical distribution of the values of this index, it may be stated that most plants in the Southwest of the province provided very high values. Therefore, it may be assumed that they present similar treatment strategies, which are very effective.

Those plants with the worst values of this index are scattered, a fact that shows that poor efficiency may be assumed as a specific problem of some plants and not as a systemic problem of some areas, which could be associated with certain geographical pollution patterns or inefficient treatment technologies implemented in a set of plants.

It is outstanding that three of the plants that provided the highest input load (Zarza, Alange and Solana) also provided very good Sustainability Indices, a fact that shows that very efficient treatment strategies are implemented in those plants. Therefore, their treatment strategies could be used as a reference for other plants to improve their performance.

All information obtained from this analysis shows that, as stated in $[13,14]$, these kinds of indices are really efficient to assess the WWTP performance and subsequently, to promote sustainable wastewater treatment processes. In [13], economic, environmental, and social issues were combined to identify those treatment technologies which were able to provide reliable performances. On the other hand, [14] provided a statistical analysis to measure the efficiency of the treatment process 
related to energy consumption. In the present work, a very simple mathematical expression has been defined to measure sustainability from variables describing the treatment state and its efficiency in a very simple way, providing valuable information to identify efficient plants and also those with a poor performance.

\section{Conclusions}

In this work, two indices have been defined to describe the pollution load that WWTPs receive and the efficiency of the treatment process they carry out. They were defined by taking into account only variables and parameters with a higher influence on the information they provided. The first index, Load, may be used to describe the overall pollution a plant receives. Its geographical representation could be useful to identify those areas which suffer from pollutant overload or are more vulnerable to industrial pollutant discharges. In the same way, those receiving a low input load may also be pointed out. In both cases, this information may be useful to define control strategies to deal with those extreme operation conditions.

The second index, Sustainability, provides a measure of how well a plant carries out its treatment process from the combined point of view of removal efficiency and energy consumption. It may be a very useful tool to identify those plants with a poor efficiency in their treatment process, regardless of whether specific removal rates (organic matter, nitrogen, ammonium ... ) are good or not. The analysis of the geographical distribution of this index may help to identify areas with a common treatment behavior. In this way, when low sustainability indices appear in a certain area, their joint study could help to identify common treatment problems, so that joint actions could be carried out to improve their efficiency. In the same way, plants with a high Sustainability Index should be studied to identify why they provide such good results, so that this information can be used to improve the performance of other plants.

All this information may be very useful for authorities supervising the performance of WWTPs, as well as for enterprises in charge of their management, because they have a tool to provide information regarding the pollution load and the overall removal efficiency of plants. The analysis of the Load Index, the geographical distribution of its values for a set of plants, and their joint study could help them to identify common pollution patterns that affect a set of plants which may be jointly managed by defining common treatment strategies. In the same way, when associating pollution patterns with sustainability, those plants performing the best may be used as a reference to improve the treatment strategies of those with a worse performance.

Finally, it is worth noting that the analysis carried out in this work has also pointed out interesting relationships between the variables usually used to analyze the process treatment behavior. They have been described when analyzing the results provided by biplots. Some of them may be useful to understand the process efficiency of some plants. Therefore, this study showed that Energy Consumption was intimately related to input flow and industrial discharges, that is to say, to the total amount of input pollution, but not to the nature and concentration of those pollutants. In this way, it is possible to evaluate this important key management parameter without studying specific removal efficiencies. Finally, it was pointed out that plants with a low Number of Industrial Discharges and low Energy Consumption showed a high removal efficiency.

Author Contributions: Data curation, M.I.F.-F.; Formal analysis, M.I.F.-F., P.T.M.d.l.V., and M.A.J.-M.; Methodology, M.I.F.-F., P.T.M.d.I.V., and M.A.J.-M.; Software, M.I.F.-F.; Validation, M.I.F.-F., P.T.M.d.I.V., and M.A.J.-M.; Writing-review \& editing, M.I.F.-F., P.T.M.d.I.V., and M.A.J.-M.

Funding: This research has been supported by the project 0066_IDIAQUA_6_E, co-founded by the Cooperation Programmes INTERREG V-A Spain-Portugal (POCTEP) 2014-2020.

Acknowledgments: The authors would like to thank PROMEDIO (Consorcio de Gestión Medioambiental de la Diputación de Badajoz) for their support, as it provided the data used in this work. 
Conflicts of Interest: The authors declare no conflict of interest. The funders had no role in the design of the study; in the collection, analyses, or interpretation of data; in the writing of the manuscript, or in the decision to publish the results.

\section{References}

1. Marshall, S.J. The Water Cycle. Reference Module in Earth Systems and Environmental Sciences; Elsevier: Amsterdam, The Netherlands, 2014. [CrossRef]

2. Shi, J. Volume 4 Overview: Water Cycle Over Land. Reference Module in Earth Systems and Environmental Sciences; Elsevier: Amsterdam, The Netherlands, 2018. [CrossRef]

3. Corominas, L.L.; Foley, J.; Guest, J.S.; Hospido, A.; Larsen, H.F.; Morera, S.; Shaw, A. Life cycle assessment applied to wastewater treatment: State of the art. Water Res. 2013, 47, 5480-5492. [CrossRef] [PubMed]

4. Peña-Guzmán, C.A.; Melgarejo, J.; Prats, D.; Torres, A.; Martínez, S. Urban Water Cycle Simulation/Management Models: A Review. Water 2017, 9, 285. [CrossRef]

5. Padrón-Páez, J.I.; De León Almaraz, S.; Román-Martínez, A. Design of sustainable municipal wastewater treatment plants. Comput. Aided Chem. Eng. 2016, 38, 1509-1514.

6. Directive 91/271/EEC-Urban Wastewater Treatment. Available online: https:/ / eur-lex.europa.eu/legalcontent/EN/ALL/? uri=celex\%3A31991L0271 (accessed on 9 November 2018).

7. Gallego, A.; Rodriguez, L.; Hospido, A.; Moreira, M.T.; Feijoo, G. Development of regional characterization factors for aquatic eutrophication. Int. J. Life Cycle Assess. 2010, 15, 32-43. [CrossRef]

8. Stutter, M.I.; Graeber, D.; EvansWade, A.J.; Withers, P.J.A. Balancing macronutrient stoichiometry to alleviate eutrophication. Sci. Total Environ. 2018, 634, 439-447. [CrossRef] [PubMed]

9. Karaouzas, I.; Smeti, E.; Vourka, A.; Vardakas, L.; Kalogianni, E. Assessing the ecological effects of water stress and pollution in a temporary river-Implications for water management. Sci. Total Environ. 2018, 618, 1591-1604. [CrossRef] [PubMed]

10. Choi, Y.Y.; Baek, S.R.; Kim, J.I.; Choi, J.W.; Hur, J.; Lee, T.U.; Park, C.J.; Lee, J.B. Characteristics and Biodegradability of Wastewater Organic Matter in Municipal Wastewater Treatment Plants Collecting Domestic Wastewater and Industrial Discharge. Water 2017, 9, 409. [CrossRef]

11. Schweitzer, L.; Noblet, J. Chapter 3.6-Water Contamination and Pollution. Green Chemistry; Elsevier: Amsterdam, The Netherlands, 2018; pp. 261-290. [CrossRef]

12. Longo, S.; Mirko d'Antoni, B.; Bongards, M.; Chaparro, A.; Cronrath, A.; Fatone, F.; Lema, J.M.; Mauricio-Iglesias, M.; Soares, A.; Hospido, A. Monitoring and diagnosis of energy consumption in wastewater treatment plants. A state of the art and proposals for improvement. Appl. Energy 2016, 179, 1251-1268. [CrossRef]

13. Molinos-Senante, M.; Gómez, T.; Garrido-Baserba, M.; Caballero, R.; Sala-Garrido, R. Assessing the sustainability of small wastewater treatment systems: A composite indicator approach. Sci. Total Environ. 2014, 497, 607-617. [CrossRef] [PubMed]

14. Gómez, T.; Gémar, G.; Molinos-Senante, M.; Sala-Garrido, R.; Caballero, R. Assessing the efficiency of wastewater treatment plants: A double-bootstrap approach. J. Clean Prod. 2017, 164, 315-324. [CrossRef]

15. APHA. Standard Methods for the Examination of Water and Wastewater; APHA: San Diego, CA, USA, 1995.

16. Yoo, C.K.; Valrolleghem, P.A.; Lee, I.B. Nonlinear modeling and adaptive monitoring with fuzzy and multivariate statistical methods in biological wastewater treatment plants. J. Biotechnol. 2003, 105, 135-163. [CrossRef]

17. Jolliffe, I. Principal Component Analysis; Springer: New York, NY, USA, 2002.

18. Ferré, L. Selection of components in principal component analysis: A comparison of methods. Comput. Stat. Data Anal. 1995, 19, 669-682. [CrossRef]

19. Kaiser, H.F. The Application of Electronic Computers to Factor Analysis. Educ. Psychol. Meas. 1960, 141-151. [CrossRef]

20. Cattell, R.B. The Scree test for the number of factors. Multivar. Behav. Res. 1966, 1, 245-276. [CrossRef] [PubMed]

21. Ledesma, R.D.; Valero-Mora, P.; Macbeth, G. The Scree Test and the Number of Factors: A Dynamic Graphics Approach, Span. J. Psychol. 2015, 18, 1-10. [CrossRef] 
22. Tzeng, O.C. On reliability and number of principal components: Joinder with Cliff and Kaiser. Percept. Motor Skill 1992, 75, 929-930. [CrossRef]

23. Gower, J.C.; Hand, D.J. Biplots. Monographs on Statistics and Applied Probability 54; Chapman \& Hall: London, UK, 1996; ISBN 0-412-71630-5. 